\title{
Official American Thoracic Society Clinical Practice Guidelines: Diagnostic Evaluation of Infants with Recurrent or Persistent Wheezing
}

\author{
Clement L. Ren*, Charles R. Esther, Jr.*, Jason S. Debley, Marianna Sockrider, Ozge Yilmaz, Nikhil Amin, \\ Alia Bazzy-Asaad, Stephanie D. Davis, Manuel Durand, Jeffrey M. Ewig, Hasan Yuksel, Enrico Lombardi, Terry L. Noah, \\ Peggy Radford, Sarath Ranganathan, Alejandro Teper, Miles Weinberger, Jan Brozek, and Kevin C. Wilson; on behalf \\ of the ATS Ad Hoc Committee on Infants with Recurrent or Persistent Wheezing
}

This official Clinical Practice Guideline of the American Thoracic Society (ATS) was approved by the ATS Board of Directors, March 2016

Background: Infantile wheezing is a common problem, but there are no guidelines for the evaluation of infants with recurrent or persistent wheezing that is not relieved or prevented by standard therapies.

Methods: An American Thoracic Society-sanctioned guideline development committee selected clinical questions related to uncertainties or controversies in the diagnostic evaluation of wheezing infants. Members of the committee conducted pragmatic evidence syntheses, which followed the Grading of Recommendations, Assessment, Development, and Evaluation (GRADE) approach. The evidence syntheses were used to inform the formulation and grading of recommendations.

Results: The pragmatic evidence syntheses identified few studies that addressed the clinical questions. The studies that were identified constituted very low-quality evidence, consisting almost exclusively of case series with risk of selection bias, indirect patient populations, and imprecise estimates. The committee made conditional recommendations to perform bronchoscopic airway survey, bronchoalveolar lavage, esophageal $\mathrm{pH}$ monitoring, and a swallowing study. It also made conditional recommendations against empiric food avoidance, upper gastrointestinal radiography, and gastrointestinal scintigraphy. Finally, the committee recommended additional research about the roles of infant pulmonary function testing and food avoidance or dietary changes, based on allergy testing.

Conclusions: Although infantile wheezing is common, there is a paucity of evidence to guide clinicians in selecting diagnostic tests for recurrent or persistent wheezing. Our committee made several conditional recommendations to guide clinicians; however, additional research that measures clinical outcomes is needed to improve our confidence in the effects of various diagnostic interventions and to allow advice to be provided with greater confidence.

\section{Overview}

Wheezing occurs commonly during infancy (1). In most cases, wheezing episodes are mild and easily treated (2). However, some infants will develop persistent or recurrent wheezing, which is often severe (3). These infants are frequently referred to pediatric pulmonology specialists for further evaluation and treatment. Guidelines for diagnostic testing exist for older children with asthma (4), but such guidelines are lacking for wheezing infants. In a 2009 survey of Assembly on Pediatrics members of the American Thoracic Society (ATS), infantile wheezing was one of the highest ranked topics for which members desired a guideline. To address this knowledge gap and interest, the ATS convened a committee of pediatric pulmonologists with clinical and research experience in infantile wheezing to develop evidence-based guidelines for the diagnostic evaluation of infantile wheezing.

For these guidelines, the committee defined infantile wheezing as recurrent or persistent episodes of wheezing in infants

\footnotetext{
*These authors contributed equally to this work.

ORCID ID: 0000-0003-4431-0644 (C.L.R.).

Correspondence and requests for reprints should be addressed to Clement L. Ren, M.D., Indiana University School of Medicine, Riley Hospital for Children, 705 Riley Hospital Drive/ROC4270, Indianapolis, IN 46202. E-mail: clren@iu.edu
}

This article has an online supplement, which is accessible from this issue's table of contents at www.atsjournals.org 


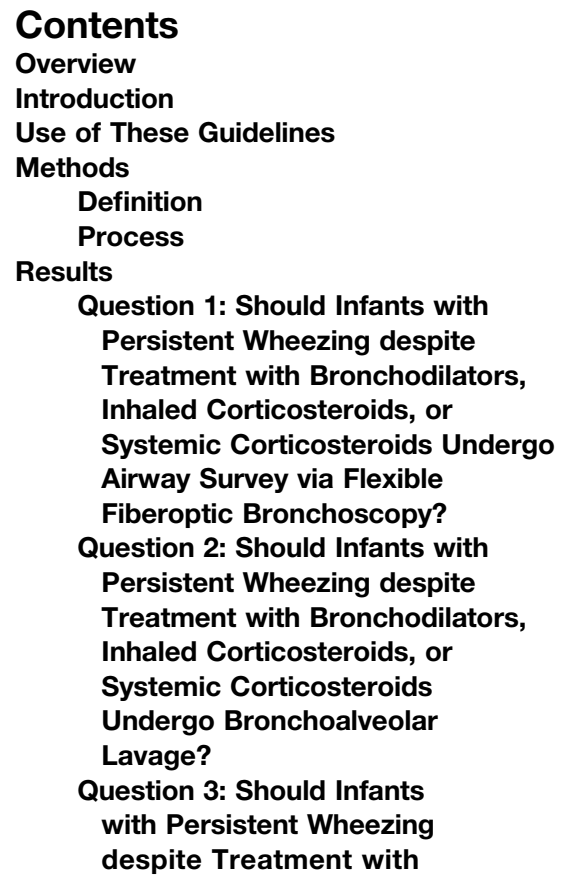

Question 3: Should Infants with Persistent Wheezing despite Treatment with

\author{
Bronchodilators, Inhaled \\ Corticosteroids, or Systemic \\ Corticosteroids Be Managed \\ according to the Results of \\ Infant Pulmonary Function \\ Testing Using the Raised-Volume \\ Rapid Thoracoabdominal \\ Compression Technique or \\ Clinical Assessment Alone? \\ Question 4: Should Infants without \\ Eczema Who Have Persistent \\ Wheezing despite Treatment with \\ Bronchodilators, Inhaled \\ Corticosteroids, or Systemic \\ Corticosteroids Undergo Empiric \\ Food Avoidance? \\ Question 5: Should Infants \\ with Persistent Wheezing despite \\ Treatment with Bronchodilators, \\ Inhaled Corticosteroids, or \\ Systemic Corticosteroids Undergo \\ 24-Hour Esophageal pH \\ Monitoring? \\ Question 6: Should Infants \\ with Persistent Wheezing despite
}

Treatment with Bronchodilators, Inhaled Corticosteroids, or Systemic Corticosteroids Undergo an Upper Gastrointestinal Series Rather Than 24-Hour Esophageal pH Monitoring?

Question 7: Should Infants

with Persistent Wheezing

That Is Not Relieved by

Bronchodilators, Inhaled

Corticosteroids, or Systemic

Corticosteroids Undergo

Gastroesophageal

Scintigraphy Rather Than

24-Hour Esophageal

pH Monitoring?

Question 8: Should Infants without

Neurologic Pathology with

Persistent Wheezing That Is Not

Relieved by Bronchodilators,

Inhaled Corticosteroids, or

Systemic Corticosteroids

Undergo a Swallowing Function

Study?

Limitations and Future Directions less than 24 months old (herein referred to as "infants with persistent wheezing"). The guidelines address diagnostic tests that are frequently considered by pediatric pulmonologists and other clinicians when evaluating infantile wheezing, but are either controversial or a frequent source of uncertainty. Diagnostic tests that are generally considered standard of care (e.g., chest radiography) were not addressed.

The committee performed a pragmatic evidence synthesis and then used the Grading of Recommendations, Assessment, Development, and Evaluation (GRADE) approach (5) to formulate and grade the following recommendations:

1. For infants with persistent wheezing despite treatment with bronchodilators, inhaled corticosteroids, or systemic corticosteroids, we suggest an airway survey via flexible fiberoptic bronchoscopy (conditional recommendation, very low quality of evidence).

2. For infants with persistent wheezing despite treatment with bronchodilators, inhaled corticosteroids, or systemic corticosteroids, we suggest bronchoalveolar lavage (BAL) (conditional recommendation, very low quality of evidence).

3. We recommend research studies in infants with persistent wheezing despite treatment with bronchodilators, inhaled corticosteroids, or systemic corticosteroids, which compare clinical outcomes among those who are managed according to results of infant pulmonary function testing using the raised-volume rapid thoracoabdominal compression (RVRTC) method versus those who are managed according to clinical assessment alone.

4. A. For infants who do not have eczema but have persistent wheezing despite treatment with bronchodilators, inhaled corticosteroids, or systemic corticosteroids, we suggest that clinicians and caregivers not use empiric food avoidance or dietary changes (conditional recommendation, very low quality of evidence).

B. We recommend research studies that determine whether food avoidance or dietary changes guided by food allergy testing improves clinical outcomes in infants who do not have eczema but have persistent wheezing despite treatment with bronchodilators, inhaled corticosteroids, or systemic corticosteroids.

5. For infants with persistent wheezing despite treatment with bronchodilators, inhaled corticosteroids, or systemic corticosteroids, we suggest 24-hour esophageal $\mathrm{pH}$ monitoring (conditional recommendation, very low quality of evidence).

6. For infants with persistent wheezing despite treatment with bronchodilators, inhaled corticosteroids, or systemic corticosteroids, we suggest 24-hour esophageal $\mathrm{pH}$ monitoring rather than upper gastrointestinal radiography (conditional recommendation, very low quality of evidence).

7. For infants with persistent wheezing despite treatment with bronchodilators, inhaled corticosteroids, or systemic corticosteroids, we suggest 24-hour esophageal $\mathrm{pH}$ monitoring rather than gastrointestinal scintigraphy (conditional recommendation, very low quality of evidence).

8. For infants with persistent wheezing despite treatment with bronchodilators, inhaled corticosteroids, or systemic corticosteroids, we suggest performing video-fluoroscopic swallowing studies (conditional recommendation, very low quality of evidence).

\section{Introduction}

Wheezing during infancy is a common clinical problem. In the Tucson Children's Respiratory Study, a longitudinal birth cohort study of healthy full-term infants, 
$34 \%$ of children had at least one episode of wheezing before age 3 years (1). In some infants, this is a sign of early-onset asthma (6), whereas other infants may wheeze because of diminished airway function or innate immune responses $(7,8)$. For the majority of infants, these wheezing episodes are mild, episodic, and easily treated. However, some infants will develop severe recurrent or persistent wheezing. Guidelines for the evaluation and treatment of asthma in older children and the general approach to the evaluation of infantile wheezing have been published $(4,9)$, but no guidelines exist for the use of more specialized testing, such as flexible fiberoptic bronchoscopy, in the evaluation of infants with persistent wheezing. Recognizing the need for clinical guidance on the diagnostic evaluation of wheezing infants, the ATS convened a guideline development committee of pediatric specialists to conduct pragmatic evidence syntheses and then use the evidence syntheses as the basis for recommendations for the evaluation of persistent wheezing in infancy.

\section{Use of These Guidelines}

These ATS guidelines are not meant to establish a standard of care. Rather, they represent an effort to summarize evidence and provide reasonable clinical recommendations based on that evidence. Clinicians, patients, third-party payers, other stakeholders, and the courts should never view these recommendations as dictates. No guidelines or recommendations can take into account all of the often compelling, unique individual clinical circumstances. Therefore, no one charged with evaluating clinicians' actions should attempt to apply the recommendations from these guidelines by rote or in a blanket fashion. These guidelines are not intended to be a comprehensive review of the evaluation of infantile wheezing, but rather to provide evidence-based recommendations for a set of specialized diagnostic tests frequently considered in the evaluation of this patient population. Clinicians will be able to use these recommendations when considering specific diagnostic tests for the evaluation of persistent wheezing. Recommendations for order or selection of diagnostic testing are beyond the scope of this document, and such decisions will vary depending on the specific clinical situation and parent preferences.

\section{Methods}

\section{Definition}

For these guidelines, the committee defined infantile wheezing as recurrent or persistent episodes of wheezing in infants less than 24 months old (herein, referred to as "infants with persistent wheezing").

This cutoff was chosen for two reasons: previous documents have addressed wheezing in preschool-aged children (3-5 yr old) (10), and wheezing on the basis of diminished airway function tends to improve by age 3 years (1). The population was further limited to infants with persistent wheezing despite treatment with recommended first-line therapies of bronchodilators, inhaled corticosteroids, or systemic corticosteroids (11).

\section{Process}

The co-chairs (C.L.R. and C.R.E.) were confirmed by the ATS Assembly on Pediatrics, Program Review Subcommittee, and Board of Directors. A guideline development committee was then assembled, which consisted of pediatric clinicians and researchers with expertise in the evaluation of wheezing during infancy. All members of the committee disclosed and were vetted for potential conflicts of interest according to the rules and procedures of the ATS. The committee then developed clinical questions, using the PICO (Patient, Intervention, Comparator, and Outcomes) framework. Each question was the basis of a pragmatic evidence synthesis, which consisted of searching the Medline and CINAHL (Cumulative Index to Nursing and Allied Health Literature) databases on the basis of prespecified search criteria, selecting studies based on prespecified selection criteria, and appraising and summarizing the evidence according to the GRADE approach. The evidence syntheses were used as the basis for the formulation of recommendations, which was based on consideration of the balance of benefits versus harms and burdens, quality of evidence, patient preferences, and cost and resource use. The recommendations were graded according to the GRADE approach. The specifics of the PICO framework, outcomes, and other methods are described in greater detail in the online supplement.

\section{Results}

\section{Question 1: Should Infants with Persistent Wheezing despite Treatment with Bronchodilators, Inhaled Corticosteroids, or Systemic Corticosteroids Undergo Airway Survey via Flexible Fiberoptic Bronchoscopy?}

Summary of evidence. Our literature search did not identify any studies that compared wheezing infants undergoing airway survey via bronchoscopy with wheezing infants who did not undergo airway survey. Therefore, our recommendation is based on 10 case series that collectively included 1,364 patients and reported that 452 of the 1,364 patients (33\%) who underwent airway survey for respiratory symptoms were found to have an anatomic abnormality known to cause wheezing (Table 1) (12-21). Lesions included tracheomalacia, bronchomalacia, tracheobronchomalacia, vascular rings, vascular slings, and airway compression by a vascular structure. No major complications were reported in any of the case series, with minor complications such as transient hypoxemia described in $5-10 \%$ of subjects.

Infants with wheezing due to tracheomalacia, bronchomalacia, or tracheobronchomalacia are typically managed by observation alone if wheezing is the only abnormality or the associated symptoms are mild, because the vast majority of infants improve over time with conservative therapy (22). Infants with wheezing due to tracheomalacia, bronchomalacia, or tracheobronchomalacia occasionally require an intervention (e.g., positive airway pressure, surgery, or stenting) because of accompanying lifethreatening airway obstruction, respiratory failure, recurrent pneumonias, or failure to thrive. Positive airway pressure immediately decreases respiratory distress, restores airway patency, and improves pulmonary function according to multiple small case series and case reports (23-30). Surgery (most commonly, aortopexy) relieves obstruction in virtually all patients with tracheomalacia, but is less effective in patients with tracheobronchomalacia or bronchomalacia according to small case series (31-37). This was illustrated by a case series in which 21 of 21 patients (100\%) had tracheomalacia corrected by aortopexy, but only 1 of 4 patients (25\%) with 


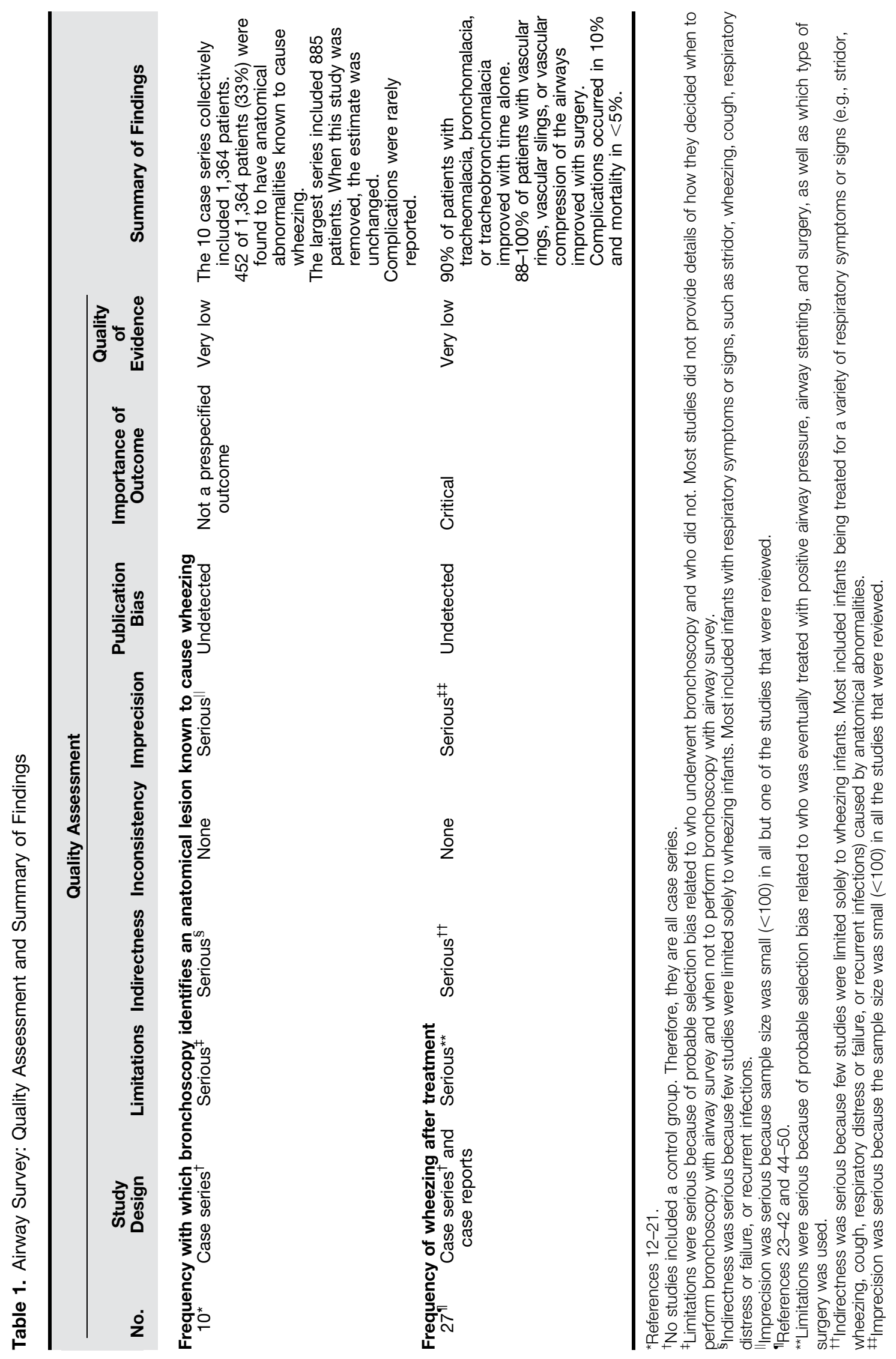


tracheobronchomalacia was corrected by aortopexy (31). Airway stenting has been used to improve airway obstruction in infants (38-42), but complications including formation of granulation tissue, migration, or erosion occurred in $50 \%$ of cases and were potentially associated with death in 2 of 22 infants $(39,40)$. Newer approaches include direct tracheobronchopexy (43).

In contrast, wheezing due to vascular rings, vascular slings, and airway compression by a vascular structure is unlikely to self-resolve, and surgical correction is performed for symptomatic patients. According to seven case series, improvement in respiratory symptoms was seen in $88-100 \%$ of patients, and complete resolution was seen in more than $50 \%$ of patients. Recurrent laryngeal nerve injury was the most common surgical complication and occurred in less than $10 \%$ of patients. More serious complications such as aortoesophageal fistula, heart failure, or wound infection associated with mortality occurred in less than $5 \%$ of patients (44-50).

Taken together, the evidence indicates that an anatomic abnormality known to cause wheezing can be identified by airway survey in approximately $33 \%$ of patients with respiratory symptoms, and in the committee's clinical experience more than $90 \%$ of such patients will improve because either their condition is self-limited or surgery can correct the abnormality. Thus, about $30 \%$ of patients are likely to benefit from an airway survey, either through direct intervention (surgery) or by avoiding unnecessary tests and treatments for a benign, self-limited condition. Identification of airway malacia may also help in management of infants believed to have concomitant asthma, because $\beta$-agonists may adversely affect airway dynamics in these children (51). The committee has very low confidence (i.e., quality of evidence) in the accuracy of these estimated effects, because the case series had probable selection bias and most series looked at infants who underwent bronchoscopy for respiratory symptoms, not specifically wheezing.

Rationale. Bronchoscopy with airway survey that identifies an anatomical cause of wheezing confers several potential benefits. Finding tracheomalacia, bronchomalacia, or tracheobronchomalacia usually leads to conservative management, which has a high success rate and other benefits including relief from the burden, cost, and potential harms of further diagnostic testing; probable reductions in the use of ineffective medications (bronchodilators or systemic corticosteroids) and the frequency of physician visits; and parental reassurance, given the high likelihood that the condition will spontaneously resolve. Finding vascular rings, vascular slings, and airway compression by a vascular structure leads to surgical therapy with an $88-100 \%$ success rate. In the judgment of the committee, the possibility that approximately $30 \%$ of infants who undergo airway survey will benefit far exceeds the burdens and cost of bronchoscopy, as well as the potential harms (i.e., complications due to bronchoscopy are rare and complications due to subsequent therapy range from zero for conservative management to approximately $10 \%$ for surgery). The recommendation for airway survey is conditional because the low quality of evidence provides little certainty that the benefits of airway survey exceed the burdens, costs, and harms. There are also emerging data on neurodevelopmental risks of anesthesia that need to be considered (52). In addition, parental preferences regarding invasive procedures tend to be highly individualized.

Recommendation 1. For infants with persistent wheezing despite treatment with bronchodilators, inhaled corticosteroids, or systemic corticosteroids, we suggest airway survey via flexible fiberoptic bronchoscopy (conditional recommendation, very low quality of evidence).

\section{Question 2: Should Infants with Persistent Wheezing despite Treatment with Bronchodilators, Inhaled Corticosteroids, or Systemic Corticosteroids Undergo Bronchoalveolar Lavage?}

Summary of evidence. Our literature search did not identify any studies that compared wheezing infants undergoing BAL with wheezing infants who did not undergo BAL. Therefore, our recommendation is based on data from 20 case series, identified in our literature search, showing that $14-80 \%$ of infants (40-60\% in most studies) with recurrent or persistent wheezing produce a positive BAL culture (Table 2) $(12,16,18$, 53-70). No complications were reported in any of the case series.

Patients with a positive BAL culture typically receive a prolonged course of antibiotic therapy, and indirect evidence from a randomized trial of 50 children with productive cough presumed to be caused by bacterial bronchitis found that the cough resolved in $48 \%$ of children who received antibiotic therapy, compared with only $16 \%$ of those who did not receive antibiotics (71). The trial likely underestimated the effects of antibiotics in patients with bacterial bronchitis because children did not need to have a confirmed bacterial infection to be enrolled in the trial; patients without bacterial bronchitis are unlikely to have responded to antibiotic therapy and, therefore, their inclusion would have made antibiotic therapy appear less effective.

On the basis of the rates of BAL infection (40-60\%) and symptom improvement with antibiotic treatment (48\%) described previously, we estimate that $20-30 \%$ of children with persistent wheezing who undergo bronchoscopy with BAL will be found to have a lower airway bacterial infection and that their symptoms will improve with antibiotic therapy. The committee's confidence in the estimated effects of BAL (i.e., the quality of evidence) is very low because it is based on prevalence estimates derived from case series and a therapeutic effect estimated from a randomized trial, both of which had serious limitations. The case series were limited by selection bias, indirectness of the population (children with cough rather than infants with wheezing), and small sample sizes with few events. The randomized trial was similarly limited by indirectness of the population (children with cough rather than infants with wheezing), indirectness of the outcome (cure of infection rather than improvement in wheezing), and imprecision (small sample size with few events).

Rationale. To confirm or exclude lower airway bacterial infection as the cause of recurrent or persistent wheezing, clinicians have three options: (1) they can perform BAL and then treat patients with confirmed bacterial infection with antibiotics;

(2) they can empirically treat all patients with empiric antibiotics; or (3) they can do neither. The committee judged the balance of the benefits versus the burdens and risks to be greater for the first option (i.e., 20-30\% children improve after treatment of BAL-identified infection) than for either the second option (i.e., the same infection cure rate, but $40-60 \%$ of patients receive unnecessary antibiotics 


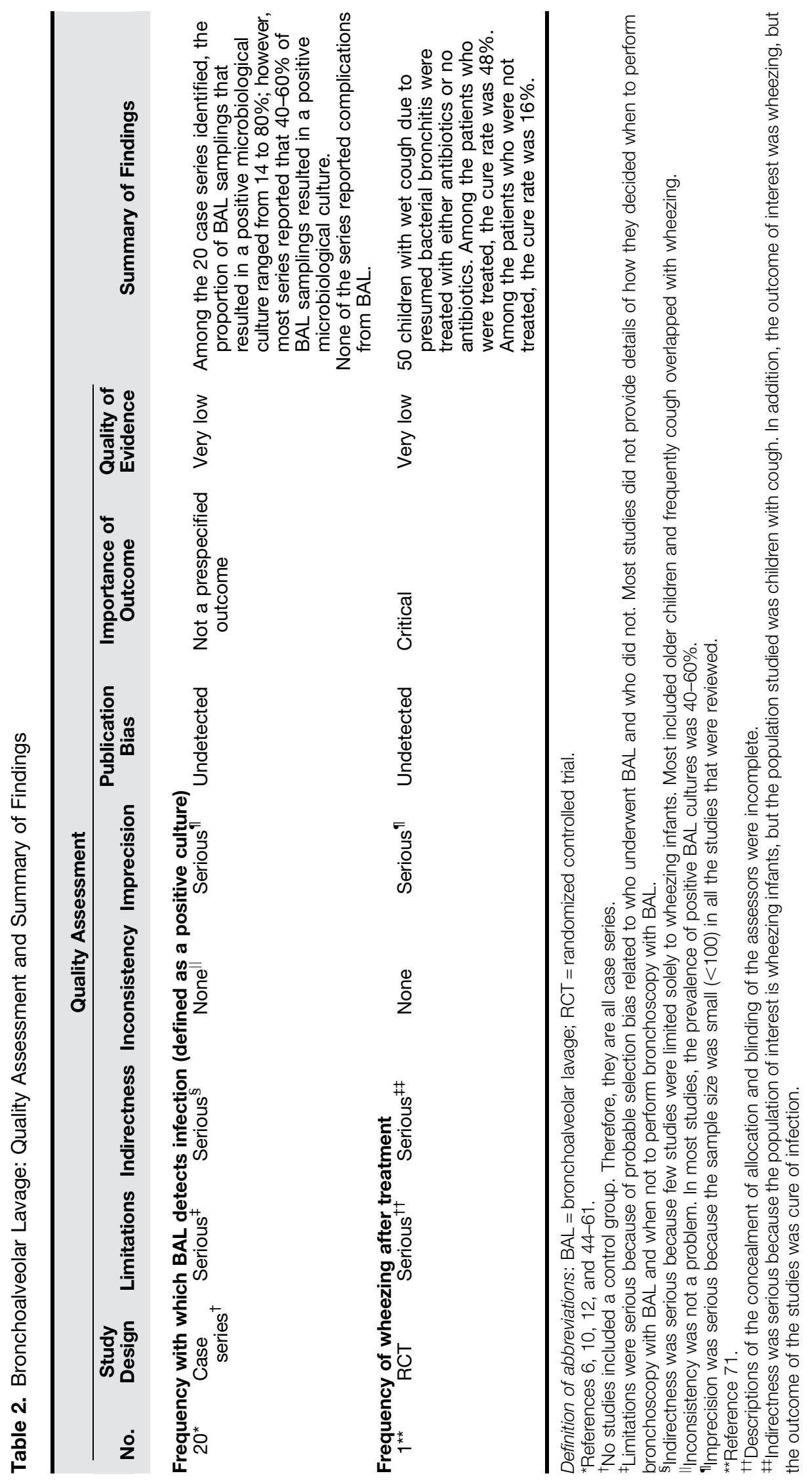


with their associated risks, such as fever, rash, anaphylaxis, acquisition of resistance, and change in gut microbiome [72]) or third option (i.e., only $6.4-9.6 \%$ infection cure rate). The committee recognized that the estimated cure rates for lower respiratory infection likely overestimate the cure rate for wheezing because some infants with lower respiratory tract bacterial infection have additional or alternative causes of wheezing; nonetheless, the committee still thought that the risk of BAL is sufficiently small that the benefits probably outweigh the burdens and harms.

The strength of the recommendation for BAL is conditional because the committee's very low confidence in the estimated effects of BAL made it impossible to be certain that the benefits of BAL outweigh the risks and burdens in the majority of patients. Moreover, BAL requires bronchoscopy, an invasive procedure requiring sedation, and it is uncertain that most families would want bronchoscopy performed on their infant, despite persistent wheezing.

Recommendation 2. For infants with persistent wheezing despite treatment with bronchodilators, inhaled corticosteroids, or systemic corticosteroids, we suggest BAL (conditional recommendation, very low quality of evidence).

\section{Question 3: Should Infants with Persistent Wheezing despite Treatment with Bronchodilators, Inhaled Corticosteroids, or Systemic Corticosteroids Be Managed according to the Results of Infant Pulmonary Function Testing Using the Raised-Volume Rapid Thoracoabdominal Compression Technique or Clinical Assessment Alone?}

Summary of evidence. Our literature search revealed 1,261 studies related to wheezing and pulmonary function tests (PFTs) in children. The overwhelming majority $(1,226$ studies) were excluded because they enrolled children during later childhood, and the guideline development committee believed that such evidence was too indirect to inform judgments for infants. Among the 35 studies that involved PFTs performed during infancy, only 2 (from the same cohort of patients at two different time points) described clinical outcomes after the assessment of bronchodilator responsiveness (BDR) using the RVRTC technique $(73,74)$. Both studies reported that the presence of BDR identified by the RVRTC technique predicted future acute exacerbations of wheezing requiring treatment with systemic corticosteroids. No studies were identified that compared the effects of management according to the BDR measured by the RVRTC technique versus management based on clinical assessment alone (i.e., no PFTs) on the clinical outcomes of interest (frequency of wheezing, frequency of doctor visits, frequency of hospitalization, prescriptions for bronchodilators, prescriptions for inhaled or systemic corticosteroids, parental stress, additional diagnostic testing, and inappropriate therapy). Thus, there was no published evidence available to inform the guideline development committee's judgments.

Rationale. In the absence of published evidence, the guideline development committee turned to its collective clinical experience to try to answer the question. However, despite extensive discussion, the guideline development committee could not reach consensus on a clinical recommendation for or against infant PFTs, due to the paucity of evidence. Some members of the committee believed that the information derived from infant PFTs did not justify the burdens and risks involved in performing the test. Among the potential benefits of confirming or excluding BDR, the clinician may be directed away or toward diagnostic testing that targets anatomical causes of wheezing, respectively. Among the risks and burdens of such testing are the need for sedation; the risks associated with airway occlusion, gastric distention, and aerophagia; the additional personnel needed to monitor the infant during and after the test; and the time and personnel needed to set up and conduct the test. Other members of the guideline development committee believed that there are circumstances in which infant PFTs are clinically useful. For example, a restrictive pattern on the PFT might lead clinicians to explore interstitial lung disease, and marked gas trapping might motivate clinicians to evaluate the infant further for neuroendocrine hyperplasia of infancy, although wheezing is usually not a common feature of this condition (75).

Recommendation 3. In infants with persistent wheezing despite treatment with bronchodilators, inhaled corticosteroids, or systemic corticosteroids, we recommend research studies that compare clinical outcomes among infants who are managed according to infant PFT performed using the RVRTC technique versus those who are managed according to clinical assessment alone.

\section{Question 4: Should Infants without Eczema Who Have Persistent Wheezing despite Treatment with Bronchodilators, Inhaled Corticosteroids, or Systemic Corticosteroids Undergo Empiric Food Avoidance?}

Summary of evidence. The National Institute of Allergy and Infectious Diseases has published clinical guidelines on food allergy in children with eczema, including recommendations for food allergy testing and avoidance in infants and children with this condition (76). Therefore, we focused our question on the role of food avoidance in infants without eczema. Our systematic review identified four studies that assessed the results of empiric food avoidance (Table 3). All of the studies measured our prespecified outcome of frequency of wheezing, but none measured any of our other prespecified outcomes, including frequency of doctor visits, frequency of hospitalization, prescriptions for bronchodilators, prescriptions for inhaled or systemic corticosteroids, parental stress, additional diagnostic testing, and inappropriate therapy. A trial randomly assigned 487 infants to receive either a cow's milk-free diet or a usual diet for at least the initial 4 months of life and found no difference in wheezing, eczema, or nasal discharge at 1 year (77). Four hundred and forty-six of the infants were reassessed 6 years later. There were still no differences in the incidence of wheezing, asthma diagnoses, eczema, or allergic rhinitis (78). Another trial randomly assigned 110 infants to receive either a partially hydrolyzed formula or standard infant formula for the first 4 months of life. There was no difference in the incidence of wheezing at 2 years, although eczema was more common among the infants who received a standard formula (79). Finally, a prospective cohort study monitored 6,905 newborns through preschool age and found no relationship between the early introduction of potentially allergenic foods (e.g., cow's milk, egg, nuts, soy, or gluten) and either wheezing or eczema at 


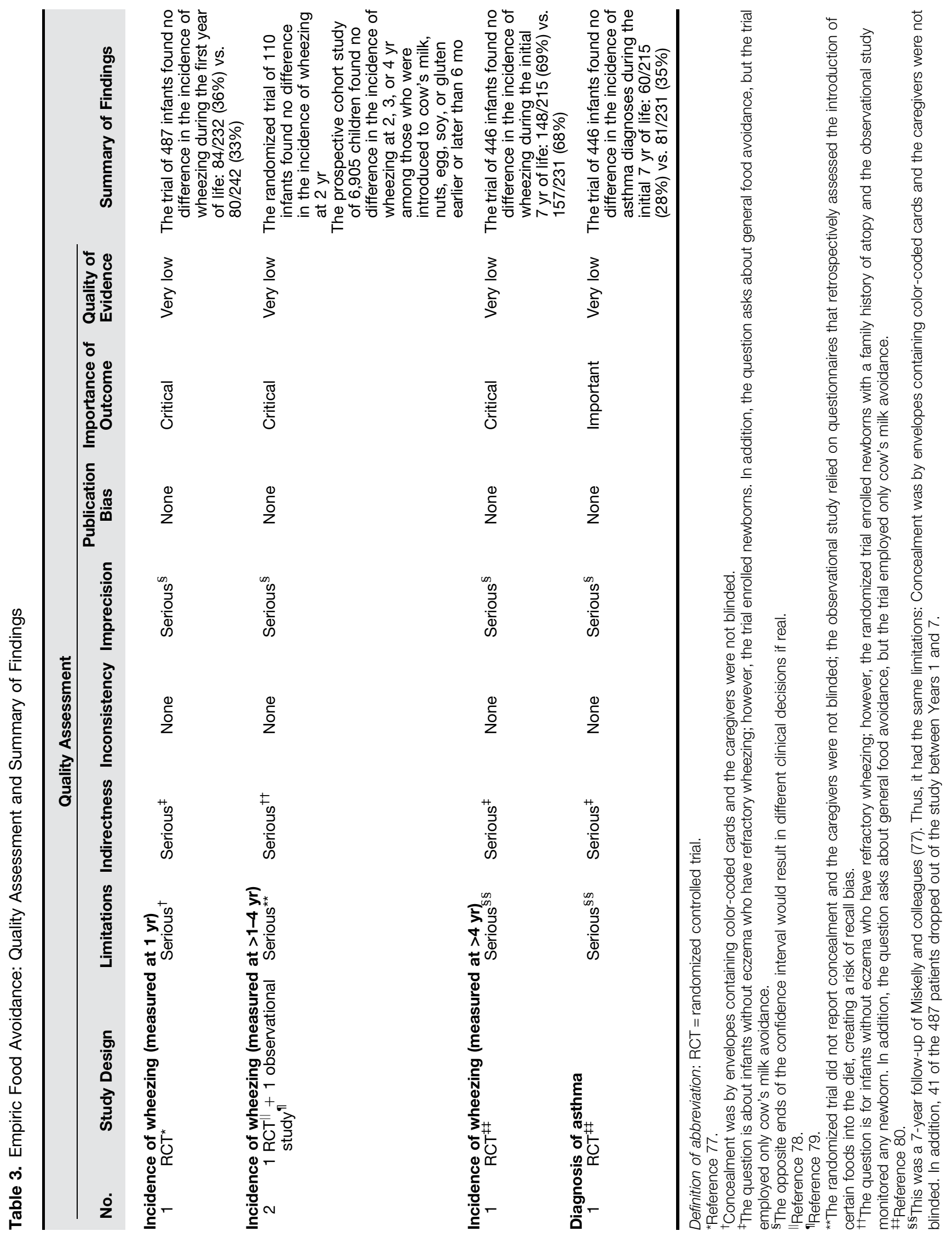


ages 2, 3, and 4 years. The study plans to monitor the participants to adulthood (80). None of the studies evaluated the effects of empiric food avoidance in a subgroup of food antigen IgE-positive infants.

Taken together, the evidence suggests that empiric food avoidance has no effect on the frequency of wheezing. However, it provides very low confidence (i.e., quality of evidence) in the estimated effects because the randomized trials were limited by risk of bias, indirectness of population and intervention, and imprecision, and the observational study was limited by possible recall bias.

Rationale. The guideline development committee chose to include questions regarding food avoidance and allergy testing because in the collective experience of the committee, parents of infants with persistent wheezing frequently raise this topic.

Although there is evidence that respiratory symptoms can be provoked by food antigens in infants with eczema (81), less is known about this relationship in infants without eczema. The guideline development committee's judgments were based on the impact of empiric food avoidance on frequency of wheezing, because our other prespecified outcomes were not reported. The lack of beneficial effects due to empiric food avoidance in any study, combined with the committee's recognition that empiric food avoidance can be burdensome, led the committee to suggest that empiric food avoidance not be used in infants without eczema who have persistent wheezing despite standard therapy. The strength of the recommendation is conditional because the very low quality of evidence prevented the committee from being certain about its judgments. In other words, although the committee believes that there is no evidence that the desirable consequences of empiric food avoidance outweigh the undesirable consequences in the majority of patients, it recognizes that there may be clinical circumstances in which a trial of empiric food avoidance may be reasonable for a minority of patients for whom the clinical history strongly correlates respiratory symptoms with food exposure or in whom respiratory symptoms are elicited in a double-blind placebocontrolled food challenge.

\section{Recommendation 4.}

A. For infants without eczema who have persistent wheezing despite treatment with standard therapies, we suggest not using empiric food avoidance (conditional recommendation, very low quality of evidence).

B. We recommend research to determine whether or not empiric food avoidance is beneficial for the subgroup of infants who are positive for IgE to food antigens.

\section{Question 5: Should Infants with Persistent Wheezing despite Treatment with Bronchodilators, Inhaled Corticosteroids, or Systemic Corticosteroids Undergo 24-Hour Esophageal pH Monitoring?}

Summary of evidence. Our systematic review did not identify any randomized trials or controlled observational studies that compared clinical outcomes among those who underwent 24-hour esophageal $\mathrm{pH}$ monitoring versus those who did not. However, we did identify three case series that used 24-hour $\mathrm{pH}$ monitoring to determine the prevalence of gastroesophageal reflux (GER) among children with wheezing and also reported the clinical outcomes that followed treatment of those with confirmed GER (Table 4) (82-84).

The most recent case series (83) enrolled 25 infants and children with asthma ( $88 \%$ had persistent wheezing) and performed 24-hour $\mathrm{pH}$ monitoring on all participants. GER was identified in 19 of $25(76 \%)$ infants and children. Participants with GER were treated with a proton pump inhibitor and reassessed at 3 months, at which time there were statistically significant improvements in symptoms (from 2.3 to 0.4 symptoms per day), use of bronchodilators (from 8.3 to $1.4 \mathrm{~d}$ per patient), use of systemic steroids (from 5.3 to $0.4 \mathrm{~d}$ per patient), frequency of exacerbations (from 1.5 to 0.3 exacerbations per patient), and hospitalizations (from 9.1 to $0.5 \mathrm{~d}$ per patient) compared with before treatment.

The case series confirmed three earlier series. In the first (82), 36 infants and children with various respiratory disorders underwent 24-hour $\mathrm{pH}$ monitoring. GER was identified in 22 of 36 infants and children (61\%), including 4 of 6 infants and children (67\%) with wheezing. Among those 22 patients, 9 patients underwent fundoplication, after which symptoms improved in 6 and resolved in 3. The remaining 13 patients with GER were treated with medical management; 9 had symptomatic improvement and 4 were lost to follow-up. In the second series (84), 12 infants with persistent wheezing despite bronchodilator and antiinflammatory therapy underwent 24-hour $\mathrm{pH}$ monitoring, and all were confirmed to have GER. They were subsequently treated with prokinetic agents and histamine receptor blockers; six improved enough to no longer require antiasthma medications, two improved enough that they required only intermittent antiasthma medications, and four failed to improve and underwent fundoplication. After fundoplication, three of the four patients no longer required antiasthma medications. In the third series (85), 81 children with recurrent pneumonias or chronic asthma underwent 24-hour $\mathrm{pH}$ monitoring, and 38 (47\%) were found to have GER. Forty patients were treated for GER (2 on the basis of alternative tests). Among the 12 children who underwent medical management, 10 improved (83\%). Among the 24 children who underwent surgical treatment, 22 improved (92\%). Four patients were lost to follow-up. None of the case series reported any adverse effects from the 24-hour $\mathrm{pH}$ monitoring or subsequent therapy.

Taken together, the evidence indicates that GER exists in $47-100 \%$ of infants with persistent wheezing and, if identified, more than $83 \%$ (most estimates are in the $90-100 \%$ range) will improve with medical or surgical treatment. However, the evidence provides very low confidence in the estimated effects. With respect to indirectness of the population, most studies included older children with a mix of respiratory problems in addition to wheezing (e.g., recurrent pneumonia, apnea, stridor, and cough) and did not evaluate the wheezing infant subgroup. With respect to indirectness of the intervention, there was variability in the methods used for 24-hour $\mathrm{pH}$ monitoring, including positioning of probes, patient positioning, dietary restrictions, scoring criteria, definitions of an abnormal study, and use of impedance data. $\mathrm{pH}$ probes detect only acid reflux unless paired with impedance; thus, not using impedance data may underestimate episodes of postprandial reflux in infants with frequent feeds and buffering of gastric contents (86). 


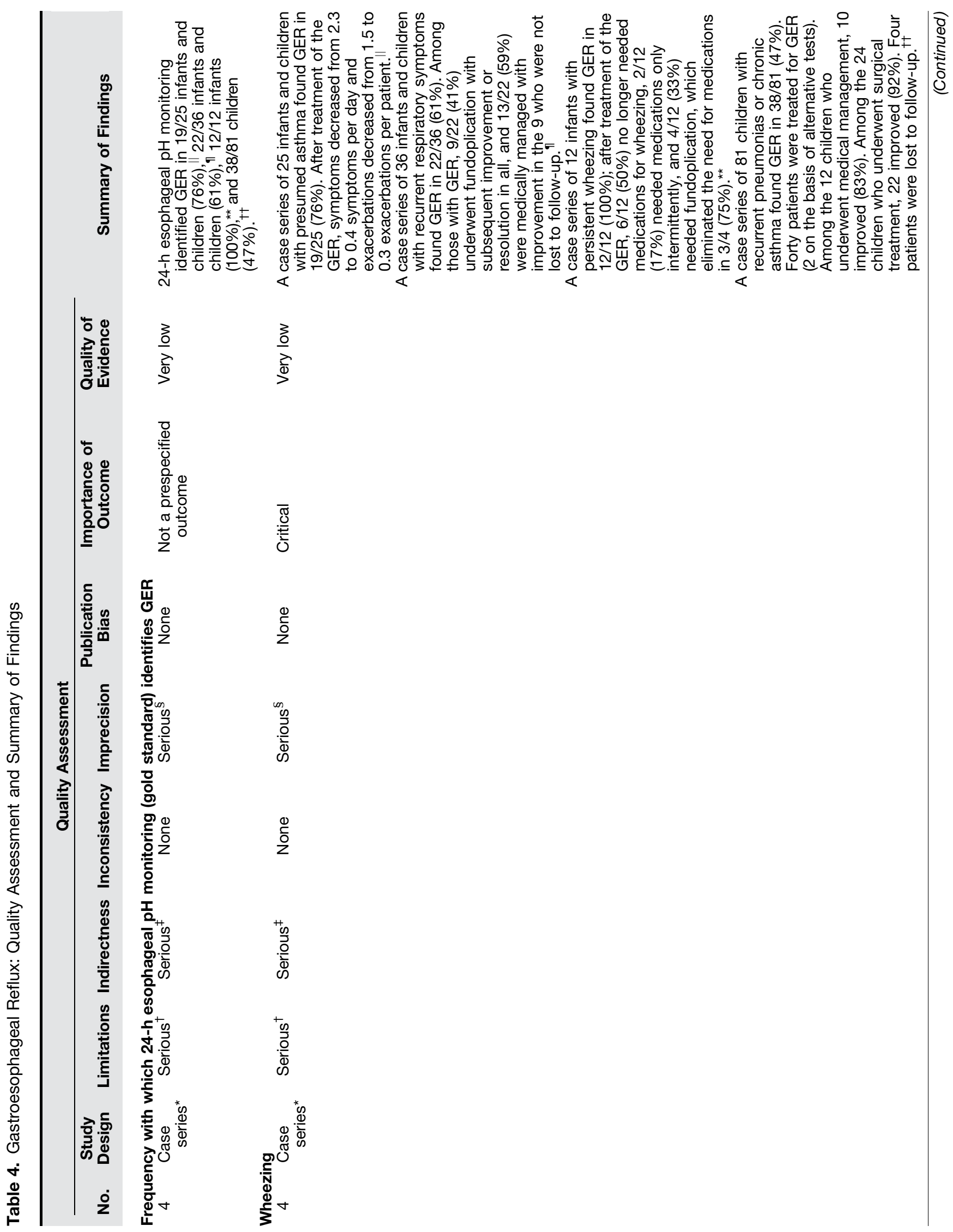




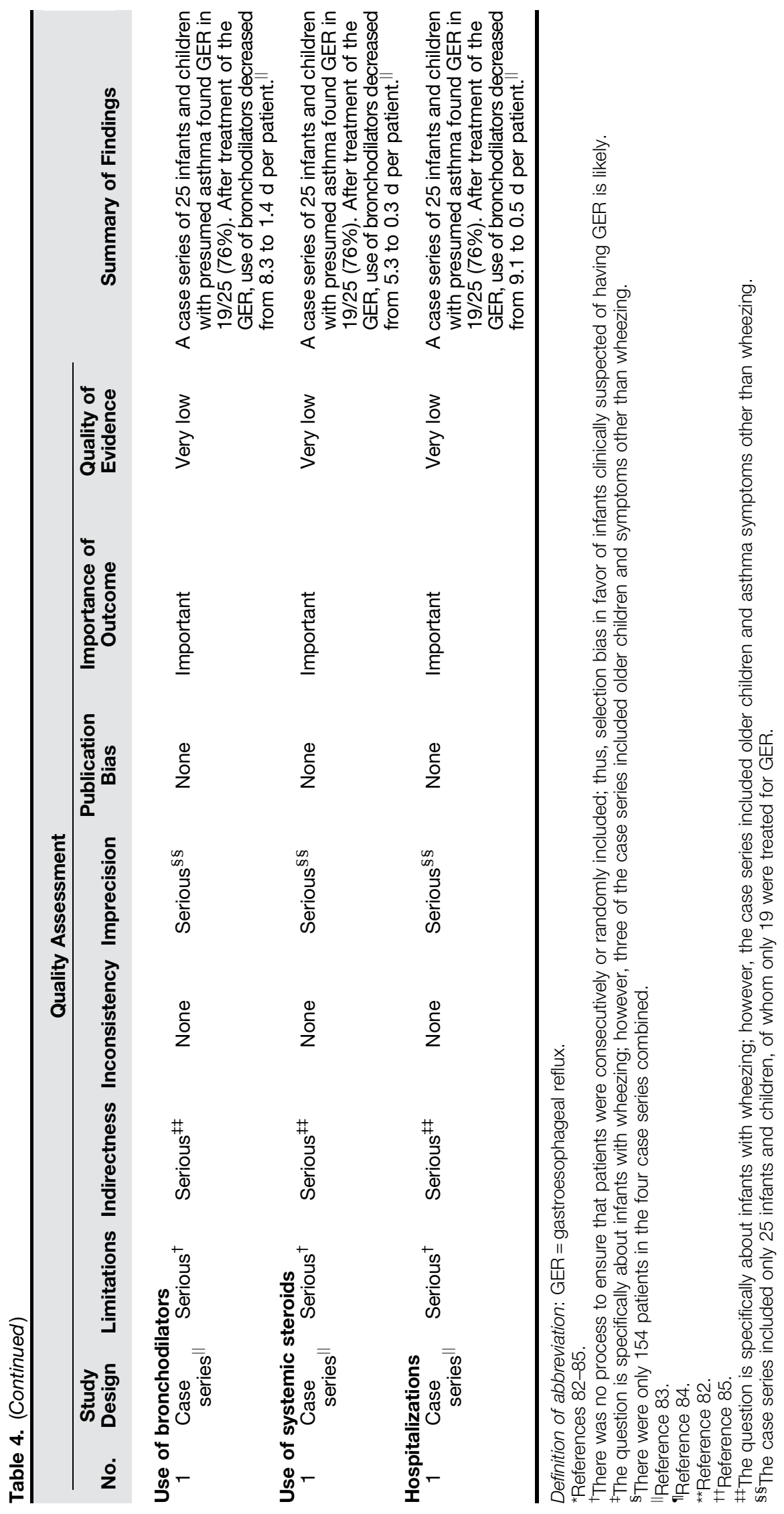


Rationale. The guideline development committee believed that the balance of benefits versus risks, burdens, and cost favors 24-hour $\mathrm{pH}$ monitoring in most infants who have persistent wheezing despite bronchodilator and antiinflammatory therapy. Specifically, among such infants who undergo 24-hour $\mathrm{pH}$ monitoring, $67-100 \%$ will be found to have GER and nearly all will improve substantially with treatment, without requiring further diagnostic testing. The procedure is well tolerated by the vast majority of patients and, although its semiinvasive nature and potential need for inpatient admission may be concerning to some parents, the committee believed that most families would be willing to have the test done. Although combined $\mathrm{pH}$ and impedance probe monitoring has become the standard at most centers, the available evidence largely predates widespread use of impedance probes. Therefore, the committee was unable to comment specifically on the value of impedance monitoring.

An alternative to 24-hour $\mathrm{pH}$ monitoring is an empiric trial of antiacid therapy. However, in up to one-third patients receiving empiric therapy, the antiacid therapy is inappropriate and incurs unnecessary cost, burden, and risk. In addition, the rate of treatment success is likely to be lower among empirically treated patients because those with GER that requires fundoplication may be incorrectly considered nonresponders. In that case, it may be presumed that GER is not a contributor and the parents may never be offered potentially curative surgical therapy. Furthermore, studies in older patients suggest that proton pump inhibitor therapy is linked to increased risk of pneumonia (87). Although a similar risk has not been reported in infants, a normal $\mathrm{pH}$ monitoring study could potentially reduce any risks associated with proton pump inhibitor therapy.

The strength of our recommendation is conditional because the very low quality of evidence provided little confidence in the estimated benefits and harms reported by the case series. As a result, the committee could not be certain about its judgments regarding the balance of benefits versus harms, burdens, and cost.

Recommendation 5. For infants with persistent wheezing that is not relieved by bronchodilators, inhaled corticosteroids, or systemic corticosteroids, we suggest 24 -hour esophageal $\mathrm{pH}$ monitoring (conditional recommendation, very low quality of evidence).

\section{Question 6: Should Infants with Persistent Wheezing despite Treatment with Bronchodilators, Inhaled Corticosteroids, or Systemic Corticosteroids Undergo an Upper Gastrointestinal Series Rather Than 24-Hour Esophageal pH Monitoring?}

Summary of evidence. The guideline development committee next asked whether an upper gastrointestinal (UGI) series is an acceptable alternative to 24-hour esophageal $\mathrm{pH}$ monitoring, which we considered the reference standard. Our systematic review did not identify any randomized trials or controlled observational studies that compared clinical outcomes among those who underwent a UGI series with those who underwent 24-hour esophageal $\mathrm{pH}$ monitoring. However, it did identify three studies that evaluated the accuracy of a UGI series in detecting GER in infants and children with wheezing (Table 4$)(82,85)$.

In the only study that used 24-hour $\mathrm{pH}$ monitoring as the reference standard, 79 children (age, 2-17 yr) who had difficultto-control asthma underwent 24-hour esophageal $\mathrm{pH}$ monitoring. GER was identified in 58 of 79 children (73\%). A barium swallow study was then performed, which identified GER with a sensitivity and specificity of 46 and $82 \%$, respectively (88).

The other two studies used various reference standards, but reported enough data to enable us to estimate the sensitivity of a UGI series in the detection of GER relative to 24-hour esophageal monitoring. In a study of infants and children (age, 2 mo-10.5 yr) with recurrent respiratory disorders (82), 22 of 36 (61\%) were found to have GER by 24-hour pH monitoring, and 15 of 35 (42\%) were found to have GER by UGI series. Assuming that patients in whom GER was detected by UGI series also had GER detected by 24 -hour $\mathrm{pH}$ monitoring, the sensitivity of a UGI series would be $68 \%$. In a study of 82 infants and children (5 mo-16 yr) with recurrent pneumonia or chronic asthma (85), 40 were found to have GER on the basis of study criteria; of these, 30 of 40 had positive UGI series results and 38 of the 39 infants who had 24-hour $\mathrm{pH}$ monitoring showed positive results (one patient did not undergo $\mathrm{pH}$ monitoring). On the basis of these numbers, the sensitivity of a UGI series would be $75 \%$, compared with $97 \%$ for $\mathrm{pH}$ monitoring. The sensitivity of a UGI series appears to be similarly poor among children without respiratory symptoms (89).

These accuracy tests constitute very low-quality evidence, meaning that they provide very low confidence in their results. The poor quality of evidence reflects the fact that the studies did not enroll consecutive patients, and it was not reported whether there was legitimate uncertainty about the presence or absence of GER.

Rationale. The primary advantages of performing a UGI series rather than 24-hour esophageal $\mathrm{pH}$ monitoring are that a UGI series can be performed less invasively and in less time. A less frequent advantage is that UGI series occasionally demonstrate pertinent anatomical abnormalities, such as hiatal hernias or esophageal indentation suggestive of a vascular ring. The disadvantages of a UGI series include radiation exposure, the need for patient cooperation, and its semiinvasive nature.

The guideline development committee made the a priori decision that the benefits of a UGI series would outweigh both the disadvantages of a UGI series and the consequences of incorrect results if the false-negative rate was less than $10 \%$ (i.e., sensitivity greater than $90 \%$ ) and the false-positive rate was less than $10 \%$ (i.e., specificity greater than $90 \%$ ). In other words, assuming a prevalence of GER of roughly $60 \%$, the committee would accept 40 false-positive results and 60 falsenegative results for every 1,000 patients tested. The acceptable false-negative and false-positive rates are both relatively small because 24-hour $\mathrm{pH}$ monitoring is not overly risky or burdensome.

The evidence indicates that the sensitivity (68-79\%) and specificity (82\%) of UGI series are insufficient to warrant the use of UGI series as an alternative to 24-hour esophageal $\mathrm{pH}$ monitoring. The recommendation against UGI series is conditional because the very low quality of evidence does not provide sufficient confidence in the estimated sensitivity and specificity to be certain that a UGI series is not a worthwhile alternative. The meaning of a conditional recommendation is that it is right for most patients, but may not be right for a sizable minority 
in certain situations. As an example, a UGI series can be a valuable tool for identifying vascular rings or slings and may be considered if such malformations are suspected. A UGI series can also be considered in circumstances in which 24-hour $\mathrm{pH}$ monitoring is not a practical option.

Recommendation 6. For infants with persistent wheezing that is not relieved by bronchodilators, inhaled corticosteroids, or systemic corticosteroids, we suggest 24-hour esophageal $\mathrm{pH}$ monitoring rather than a UGI series (conditional recommendation, very low quality of evidence).

\section{Question 7: Should Infants with Persistent Wheezing That Is Not Relieved by Bronchodilators, Inhaled Corticosteroids, or Systemic Corticosteroids Undergo Gastroesophageal Scintigraphy Rather Than 24-Hour Esophageal pH Monitoring?}

Summary of evidence. The guideline development committee next asked whether gastroesophageal scintigraphy is an acceptable alternative to 24-hour $\mathrm{pH}$ monitoring, which we considered the reference standard. Our systematic review did not identify any randomized trials or controlled observational studies that compared clinical outcomes among those who underwent scintigraphy with those who underwent 24-hour esophageal pH monitoring. However, it did identify four studies that evaluated gastroesophageal scintigraphic detection of GER in infants and children with wheezing.

In the only study that used 24-hour $\mathrm{pH}$ monitoring as the reference standard, 79 children (age, 2-17 yr) who had difficult-to-control asthma underwent 24-hour esophageal $\mathrm{pH}$ monitoring. Gastroesophageal scintigraphy identified GER with a sensitivity and specificity of 15 and $73 \%$, respectively (88). Another study of infants with wheezing used clinical history and a response to anti-GER therapy as the reference standard instead of 24-hour $\mathrm{pH}$ monitoring. It found that gastroesophageal scintigraphy detected GER with a sensitivity and specificity of 58 and $85 \%$, respectively, when a history compatible with GER was used as the reference standard, and with a sensitivity and specificity of 79 and 50\%, respectively, when a response to anti-GER therapy was used as the reference standard (90). Finally, two studies did not compare gastroesophageal scintigraphy with a reference standard, but rather, reported that the technique identified GER in 22\% of infants and children (age, 3 mo-4 yr) who presented with recurrent wheezing or vomiting (91) and in $26 \%$ of infants and children (age, 6 mo-6 yr) who presented with difficult-to-treat asthma (92); these yields were lower than the 67-100\% described previously for 24-hour esophageal $\mathrm{pH}$ monitoring. The sensitivity of gastroesophageal scintigraphy appears to be similarly poor among infants and children without respiratory symptoms (89).

These accuracy studies constitute very low quality of evidence, meaning that they provide very low confidence in their estimated effects. The poor quality of evidence reflects the fact that the studies did not enroll consecutive patients, and it was not reported whether there was legitimate uncertainty about the presence or absence of GER. Moreover, there was indirectness of the population because our focus was on wheezing infants, but many of the studies enrolled older children.

Rationale. The primary advantages of gastroesophageal scintigraphy rather than 24-hour esophageal $\mathrm{pH}$ monitoring are that scintigraphy can be performed less invasively and in less time. The disadvantages of scintigraphy are primarily radiation exposure (albeit less than that required for a UGI series) and high cost.

The guideline development committee made an $a$ priori decision that the advantages of gastroesophageal scintigraphy would outweigh the disadvantages associated with potential incorrect results if the false-negative rate was less than $10 \%$ (i.e., sensitivity greater than $90 \%$ ) and the false-positive rate was less than $10 \%$ (i.e., specificity greater than $90 \%$ ). In other words, assuming a prevalence of GER of roughly $60 \%$, the committee would accept 40 false-positive results and 60 falsenegative results for every 1,000 patients tested. The acceptable false-negative and false-positive rates are both relatively small because 24-hour $\mathrm{pH}$ monitoring is not overly risky or burdensome.

The evidence indicates that the sensitivity and specificity (15 and $73 \%$, respectively) of gastroesophageal scintigraphy are insufficient to warrant the use of scintigraphy as an alternative to 24-hour esophageal $\mathrm{pH}$ monitoring. The recommendation against scintigraphy is conditional because the very low quality of evidence does not provide sufficient confidence in the estimated sensitivity and specificity to be certain that scintigraphy is not a worthwhile alternative.

Recommendation 7. For infants with persistent wheezing that is not relieved by bronchodilators, inhaled corticosteroids, or systemic corticosteroids, we suggest 24 -hour esophageal $\mathrm{pH}$ monitoring rather than gastrointestinal scintigraphy (conditional recommendation, very low quality of evidence).

\section{Question 8: Should Infants without Neurologic Pathology with Persistent Wheezing That Is Not Relieved by Bronchodilators, Inhaled Corticosteroids, or Systemic Corticosteroids Undergo a Swallowing Function Study?}

Summary of evidence. Our literature review did not identify any randomized trials or controlled observational studies that compared clinical outcomes among those who underwent a swallowing function study versus those who did not. However, it did identify two case series that reported the prevalence of aspiration detected by video-fluoroscopic swallowing function studies in infants and children who did not have chronic illnesses but did have respiratory symptoms including wheezing (Table 5). Both series also reported the outcomes of treatment $(93,94)$.

The first series enrolled 472 infants (age, $<1$ yr) with either respiratory symptoms or vomiting and performed fluoroscopic swallowing studies on each. Swallowing dysfunction was detected in 63 of 472 infants (13\%). Among these infants, $70 \%$ had tracheal aspiration and $30 \%$ had laryngeal penetration. Because the coordination of swallowing improves with age among infants without chronic illnesses, the infants with swallowing dysfunction were managed by thickening the consistency of their food. Tracheal aspiration or laryngeal penetration was seen in 179 swallowing studies with thin liquids, 61 studies with thickened liquids, and 14 studies with pureed food (93).

The second case series included 112 infants (age, $<1 \mathrm{yr}$ ) with wheezing or intermittent stridor and performed video- 


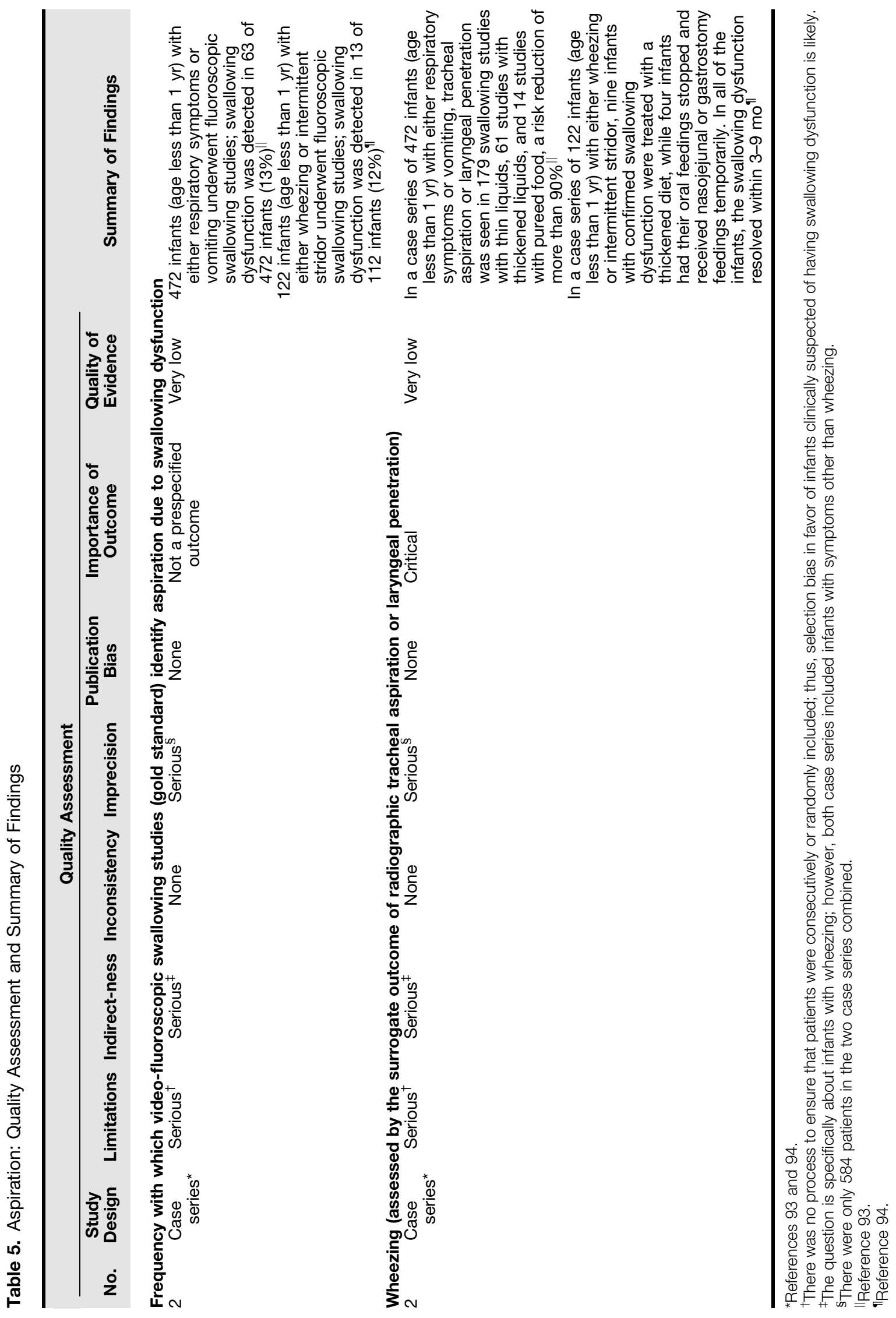


fluoroscopic swallowing function studies on each. Swallowing dysfunction was detected in 13 of 112 infants (12\%). Nine infants were treated with a thickened diet, and four infants had their oral feedings stopped and received nasojejunal or gastrostomy feedings temporarily. In all of the infants, the swallowing dysfunction resolved within 3-9 months (94).

Taken together, the evidence suggests that swallowing dysfunction, which is known to cause wheezing, can be identified by video-fluoroscopic swallowing studies in $10-15 \%$ of infants who do not have a chronic illness but have respiratory symptoms. More than $90 \%$ of such patients will improve with feeding interventions while waiting for the swallowing coordination to improve with age. Thus, $9-14 \%$ of patients who undergo videofluoroscopic swallowing studies may derive some benefit. The committee has very low confidence (i.e., quality of evidence) in the accuracy of these estimated effects because the study designs were case series (i.e., they were uncontrolled); and there was risk for indirectness (i.e., most series looked at infants who had a variety of respiratory symptoms, not specifically wheezing).

Rationale. A video-fluoroscopic swallowing study confers several potential benefits. Finding swallowing dysfunction usually leads to feeding modifications that reduce aspiration by approximately $90 \%$; a reduction in aspiration is a surrogate outcome for persistent wheezing, stridor, cough, and pneumonia. Other benefits include relief from the burden, cost, and potential harms of further diagnostic testing; probable reductions in the use of ineffective medications (bronchodilators or inhaled corticosteroids) and the frequency of physician visits; and parental reassurance given the high likelihood that the condition will spontaneously resolve. Limitations include the need for infant/child cooperation, cost, availability of speech pathologist, and the risk of aspiration during the study. The committee judged that the desirable consequences outweigh the undesirable consequences and, therefore, suggests that infants with persistent wheezing that has not responded to conventional therapies undergo a video-fluoroscopic swallowing study. The recommendation is conditional because the very low quality of evidence provides little certainty that the benefits of a video-fluoroscopic swallowing study exceed the burdens, costs, and harms.

Recommendation 8. For infants without neurologic pathology with persistent wheezing that is not relieved by bronchodilators, inhaled corticosteroids, or systemic corticosteroids, we suggest a swallowing function study to evaluate for aspiration (weak recommendation, very low quality of evidence).

\section{Limitations and Future Directions}

A common theme throughout our guideline development was the striking paucity of data regarding infantile wheezing. Despite how widespread and common this clinical problem is, we were unable to find any large clinical studies that used consistent case definitions and outcomes. Most of the studies cited were case series, providing the lowest quality of evidence on the GRADE scale. Given the frequency with which infantile wheezing occurs, there is an urgent need for more rigorous research to be conducted in this field.

Although we used the GRADE methodology, we rarely had patientimportant outcomes that could be reliably linked to performance of the various diagnostic tests. As a result, we presumed that treatment strategies based on a positive test would provide therapeutic benefit to the patient, but this presumption and limited evidence reduced our ability to make strong recommendations.

One clear need for future research is to determine whether implementation of these tests actually leads to treatment that improves patient-important outcomes. Outcome measures should include both clinical responses and parental preferences, particularly regarding choices between diagnostic testing and empiric treatment. However, study design is complicated by the fact that a substantial fraction of infants with persistent wheeze not responsive to standard therapies have anatomic abnormalities that may not respond to any medical therapy. Routine incorporation of bronchoscopy into clinical trials could address this issue, but likely would be problematic given the relatively high costs and risks associated with this procedure.

This issue highlights the fact that many current tests involve substantial costs and/or risks that limit widespread use. Further research should address whether diagnosis could be achieved by less invasive tests, radiologic studies in lieu of bronchoscopy for anatomic abnormalities, or analysis of exhaled breath to detect markers of airway infection or reflux. Comparative effectiveness studies and the development of clinical pathways would also help clinicians better evaluate infants with persistent wheezing.

In summary, this document provides guidelines that further two goals of interest to the ATS. First, they will aid the pediatric generalist or respiratory specialist in the management of the infant with recurrent or persistent wheeze that does not respond to conventional therapies. Second, they will serve to identify the research needed to improve diagnosis and treatment of this vulnerable population.

This clinical practice guideline was prepared by an ad hoc subcommittee of the ATS Assembly on Pediatrics.

\section{Members of the subcommittee are as follows:}

Clement L. Ren, M.D. (Co-Chair)

Charles R. Esther, JR., M.D., Ph.D. (Co-Chair)

Jason S. Debley, M.D., M.P.H.

Marianna Sockrider, M.D., M.P.H., D.P.H.

Ozge Yilmaz, M.D.
NikHil Amin, M.D.

Alia Bazzy-AsaAd, M.D.

Stephanie D. Davis, M.D.

Manuel Durand, M.D.

JeFFrey M. EWIG, M.D.

Hasan Yuksel, M.D.

ENRICO LOMBARDI, M.D.
Terry L. Noah, M.D.

Peggy Radford, M.D.

Sarath Ranganathan, M.D.

Alejandro Teper, M.D.

Miles Weinberger, M.D.

Jan Brozek, M.D., Ph.D.

Kevin C. Wilson, M.D. 
Author Disclosures: O.Y. received conference travel support from Allergopharma Turkey and GlaxoSmithKline. N.A. was previously employed by MannKind Corp. and has been an employee of Regeneron Pharmaceuticals since January 2016 (subsequent to guideline completion). S.D.D. was on an advisory committee and a consultant for Vertex Pharmaceuticals, was a consultant for Eli Lilly and Co., and was a speaker for ABCOMM in an activity supported by Gilead. H.Y. was a speaker for
GlaxoSmithKline and Merck Sharp Dohme, and received conference travel support from Allergopharma, GlaxoSmithKline, and Nutricia E.L. was a speaker and on a data safety and monitoring board for Chiesi, received conference travel support from Lusofarmaco, was on an advisory committee and a speaker for Novartis, was a speaker for Sigma-Tau, and participated in meetings organized by his institution that were sponsored by CareFusion, Cosmed, Italchimici, Stewart Italia, and Valeas. C.L.R., C.R.E., J.S.D.,
M.S., A.B-A., M.D., J.M.E., T.L.N., P.R., S.R., A.T., M.W., J.B., and K.C.W. reported no relationships with relevant commercia interests.

Acknowledgment: The committee would like to acknowledge the invaluable efforts of Angela Dixon from the University of Rochester (Rochester, NY) for her work as the medical librarian on this project.

\section{References}

1. Martinez FD, Wright AL, Taussig LM, Holberg CJ, Halonen M, Morgan WJ; Group Health Medical Associates. Asthma and wheezing in the first six years of life. N Engl J Med 1995;332:133-138.

2. Devulapalli CS, Carlsen KC, Håland G, Munthe-Kaas MC, Pettersen M, Mowinckel P, Carlsen KH. Severity of obstructive airways disease by age 2 years predicts asthma at 10 years of age. Thorax 2008;63: 8-13.

3. Bacharier LB, Phillips BR, Bloomberg GR, Zeiger RS, Paul IM, Krawiec M, Guilbert T, Chinchilli VM, Strunk RC; Childhood Asthma Research and Education Network, National Heart, Lung, and Blood Institute. Severe intermittent wheezing in preschool children: a distinct phenotype. J Allergy Clin Immunol 2007;119:604-610.

4. National Asthma Education and Prevention Program. Expert Panel Report 3 (EPR-3): guidelines for the diagnosis and management of asthma-summary report 2007. J Allergy Clin Immunol 2007;120(5, Suppl):S94-S138. [Published erratum appears in J Allergy Clin Immunol 121:1330.]

5. Schünemann HJ, Jaeschke R, Cook DJ, Bria WF, El-Solh AA, Ernst A, Fahy BF, Gould MK, Horan KL, Krishnan JA, et al.; ATS Documents Development and Implementation Committee. An official ATS statement: grading the quality of evidence and strength of recommendations in ATS guidelines and recommendations. Am J Respir Crit Care Med 2006;174:605-614.

6. Skoner D, Caliguiri L. The wheezing infant. Pediatr Clin North Am 1988; 35:1011-1030.

7. Martinez FD, Morgan WJ, Wright AL, Holberg CJ, Taussig LM. Diminished lung function as a predisposing factor for wheezing respiratory illness in infants. N Engl J Med 1988;319:1112-1117.

8. Guerra S, Lohman IC, Halonen M, Martinez FD, Wright AL. Reduced interferon $\gamma$ production and soluble CD14 levels in early life predict recurrent wheezing by 1 year of age. Am J Respir Crit Care Med 2004; 169:70-76.

9. Kliegman RM, editor. Nelson textbook of pediatrics, 20th ed. Philadelphia, PA: Elsevier; 2016.

10. Brand PL, Baraldi E, Bisgaard H, Boner AL, Castro-Rodriguez JA, Custovic A, de Blic J, de Jongste JC, Eber E, Everard ML, et al. Definition, assessment and treatment of wheezing disorders in preschool children: an evidence-based approach. Eur Respir J 2008; 32:1096-1110.

11. Ducharme FM, Tse SM, Chauhan B. Diagnosis, management, and prognosis of preschool wheeze. Lancet 2014;383:1593-1604.

12. Aslan AT, Kiper N, Dogru D, Karagoz AH, Ozcelik U, Yalcin E. Diagnostic value of flexible bronchoscopy in children with persistent and recurrent wheezing. Allergy Asthma Proc 2005;26: 483-486.

13. Baraldi E, Donegà S, Carraro S, Farina M, Barbato A, Cutrone $C$. Tracheobronchomalacia in wheezing young children poorly responsive to asthma therapy. Allergy 2010;65:1064-1065.

14. Cakir E, Ersu RH, Uyan ZS, Oktem S, Karadag B, Yapar O, Pamukcu O, Karakoc F, Dagli E. Flexible bronchoscopy as a valuable tool in the evaluation of persistent wheezing in children. Int $J$ Pediatr Otorhinolaryngol 2009;73:1666-1668.
15. Hauk PJ, Krawiec M, Murphy J, Boguniewicz J, Schiltz A, Goleva E, Liu $\mathrm{AH}$, Leung DY. Neutrophilic airway inflammation and association with bacterial lipopolysaccharide in children with asthma and wheezing. Pediatr Pulmonol 2008;43:916-923.

16. Le Bourgeois M, Goncalves M, Le Clainche L, Benoist MR, Fournet $\mathrm{JC}$, Scheinmann P, de Blic J. Bronchoalveolar cells in children $<3$ years old with severe recurrent wheezing. Chest 2002;122: 791-797.

17. Masters IB, Chang AB, Patterson L, Wainwright C, Buntain H, Dean BW, Francis PW. Series of laryngomalacia, tracheomalacia, and bronchomalacia disorders and their associations with other conditions in children. Pediatr Pulmonol 2002;34:189-195.

18. Saglani S, Nicholson AG, Scallan M, Balfour-Lynn I, Rosenthal M, Payne DN, Bush A. Investigation of young children with severe recurrent wheeze: any clinical benefit? Eur Respir J 2006;27: 29-35.

19. Saito J, Harris WT, Gelfond J, Noah TL, Leigh MW, Johnson R, Davis SD. Physiologic, bronchoscopic, and bronchoalveolar lavage fluid findings in young children with recurrent wheeze and cough. Pediatr Pulmonol 2006;41:709-719.

20. Ullmann N, Sacco O, Gandullia P, Silvestri M, Pistorio A, Barabino A, Disma NM, Rossi GA. Usefulness and safety of double endoscopy in children with gastroesophageal reflux and respiratory symptoms. Respir Med 2010;104:593-599.

21. De Baets F, De Schutter I, Aarts C, Haerynck F, Van Daele S, De Wachter E, Malfroot A, Schelstraete P. Malacia, inflammation and bronchoalveolar lavage culture in children with persistent respiratory symptoms. Eur Respir J 2012;39:392-395.

22. Laberge J-M, Puligandla P. Congenital malformations of the lungs and airways. In: Taussig LM, Landau LI, Le Souëf PN, Martinez FD, Morgan WJ, Sly PD, eds. Pediatric respiratory medicine, 2nd ed. Philadelphia, PA: Mosby; 2008. pp. 907-942.

23. Davis S, Jones M, Kisling J, Angelicchio C, Tepper RS. Effect of continuous positive airway pressure on forced expiratory flows in infants with tracheomalacia. Am J Respir Crit Care Med 1998; 158:148-152.

24. Wiseman NE, Duncan PG, Cameron CB. Management of tracheobronchomalacia with continuous positive airway pressure. $J$ Pediatr Surg 1985;20:489-493.

25. Reiterer F, Eber E, Zach MS, Müller W. Management of severe congenital tracheobronchomalacia by continuous positive airway pressure and tidal breathing flow-volume loop analysis. Pediatr Pulmonol 1994;17:401-403.

26. Pizer BL, Freeland AP, Wilkinson AR. Prolonged positive airway pressure for severe neonatal tracheobronchomalacia. Arch Dis Child 1986;61:908-909.

27. Miller RW, Pollack MM, Murphy TM, Fink RJ. Effectiveness of continuous positive airway pressure in the treatment of bronchomalacia in infants: a bronchoscopic documentation. Crit Care Med 1986;14:125-127.

28. Ferguson GT, Benoist J. Nasal continuous positive airway pressure in the treatment of tracheobronchomalacia. Am Rev Respir Dis 1993; 147:457-461.

29. Neijens HJ, Kerrebijn KF, Smalhout B. Successful treatment with CPAP of two infants with bronchomalacia. Acta Paediatr Scand 1978;67: 293-296. 
30. Panitch HB, Allen JL, Alpert BE, Schidlow DV. Effects of CPAP on lung mechanics in infants with acquired tracheobronchomalacia. Am J Respir Crit Care Med 1994;150:1341-1346.

31. Blair GK, Cohen R, Filler RM. Treatment of tracheomalacia: eight years' experience. J Pediatr Surg 1986;21:781-785.

32. Kamata S, Usui N, Sawai T, Nose K, Kitayama Y, Okuyama H, Okada A. Pexis of the great vessels for patients with tracheobronchomalacia in infancy. J Pediatr Surg 2000;35:454-457.

33. Greenholz SK, Karrer FM, Lilly JR. Contemporary surgery of tracheomalacia. J Pediatr Surg 1986;21:511-514.

34. Morabito A, MacKinnon E, Alizai N, Asero L, Bianchi A. The anterior mediastinal approach for management of tracheomalacia. $J$ Pediatr Surg 2000;35:1456-1458.

35. Abdel-Rahman U, Ahrens P, Fieguth HG, Kitz R, Heller K, Moritz A. Surgical treatment of tracheomalacia by bronchoscopic monitored aortopexy in infants and children. Ann Thorac Surg 2002;74: 315-319.

36. Bullard KM, Scott Adzick N, Harrison MR. A mediastinal window approach to aortopexy. J Pediatr Surg 1997;32:680-681.

37. Delgado MD, Matute JA, Jimenez MA, Aguado P, Benavent MI, Filler RM, Berchi FJ. [The treatment of the tracheobronchomalacia in pediatric age] [article in Spanish]. Cir Pediatr 1997;10:65-69.

38. Tazuke Y, Kawahara H, Yagi M, Yoneda A, Soh H, Maeda K, Yamamoto T, Imura K. Use of a Palmaz stent for tracheomalacia: case report of an infant with esophageal atresia. J Pediatr Surg 1999; 34:1291-1293.

39. Filler RM, Forte V, Chait $P$. Tracheobronchial stenting for the treatment of airway obstruction. J Pediatr Surg 1998;33:304-311.

40. Furman RH, Backer CL, Dunham ME, Donaldson J, Mavroudis C, Holinger LD. The use of balloon-expandable metallic stents in the treatment of pediatric tracheomalacia and bronchomalacia. Arch Otolaryngol Head Neck Surg 1999;125:203-207.

41. Casiano RR, Numa WA, Nurko YJ. Efficacy of transoral intraluminal Wallstents for tracheal stenosis or tracheomalacia. Laryngoscope 2000;110:1607-1612.

42. Tsugawa C, Nishijima E, Muraji T, Yoshimura M, Tsubota N, Asano H. A shape memory airway stent for tracheobronchomalacia in children: an experimental and clinical study. J Pediatr Surg 1997; 32:50-53.

43. Bairdain S, Smithers CJ, Hamilton TE, Zurakowski D, Rhein L, Foker JE, Baird C, Jennings RW. Direct tracheobronchopexy to correct airway collapse due to severe tracheobronchomalacia: short-term outcomes in a series of 20 patients. J Pediatr Surg 2015;50: 972-977.

44. Shah RK, Mora BN, Bacha E, Sena LM, Buonomo C, Del Nido P, Rahbar R. The presentation and management of vascular rings: an otolaryngology perspective. Int J Pediatr Otorhinolaryngol 2007;71: 57-62.

45. Greenhill ED, Skinner K. Impaired nursing students: an intervention program. J Nurs Educ 1991;30:379-381.

46. Woods RK, Sharp RJ, Holcomb GW III, Snyder CL, Lofland GK, Ashcraft KW, Holder TM. Vascular anomalies and tracheoesophageal compression: a single institution's 25-year experience. Ann Thorac Surg 2001;72:434-438, discussion 438-439.

47. Koontz CS, Bhatia A, Forbess J, Wulkan ML. Video-assisted thoracoscopic division of vascular rings in pediatric patients. $A m$ Surg 2005;71:289-291.

48. Al-Bassam A, Saquib Mallick M, Al-Qahtani A, Al-Tokhais T, Gado A, Al-Boukai A, Thalag A, Alsaadi M. Thoracoscopic division of vascular rings in infants and children. J Pediatr Surg 2007;42:1357-1361.

49. Suematsu Y, Mora BN, Mihaljevic T, del Nido PJ. Totally endoscopic robotic-assisted repair of patent ductus arteriosus and vascular ring in children. Ann Thorac Surg 2005;80:2309-2313.

50. Kogon BE, Forbess JM, Wulkan ML, Kirshbom PM, Kanter KR. Videoassisted thoracoscopic surgery: is it a superior technique for the division of vascular rings in children? Congenit Heart Dis 2007;2: 130-133.

51. Panitch HB, Keklikian EN, Motley RA, Wolfson MR, Schidlow DV. Effect of altering smooth muscle tone on maximal expiratory flows in patients with tracheomalacia. Pediatr Pulmonol 1990;9:170-176.
52. Rappaport BA, Suresh S, Hertz S, Evers AS, Orser BA. Anesthetic neurotoxicity-clinical implications of animal models. $N$ Engl J Med 2015;372:796-797.

53. Schellhase DE, Fawcett DD, Schutze GE, Lensing SY, Tryka AF. Clinical utility of flexible bronchoscopy and bronchoalveolar lavage in young children with recurrent wheezing. J Pediatr 1998;132: 312-318

54. Marguet C, Jouen-Boedes F, Dean TP, Warner JO. Bronchoalveolar cell profiles in children with asthma, infantile wheeze, chronic cough, or cystic fibrosis. Am J Respir Crit Care Med 1999;159: 1533-1540.

55. Fayon M, Just J, Thien HV, Chiba T, Pascual L, Sandouk G, Grimfeld A. Bacterial flora of the lower respiratory tract in children with bronchial asthma. Acta Paediatr 1999;88:1216-1222.

56. Marguet C, Dean TP, Warner JO. Soluble intercellular adhesion molecule-1 (sICAM-1) and interferon- $\gamma$ in bronchoalveolar lavage fluid from children with airway diseases. Am J Respir Crit Care Med 2000;162:1016-1022.

57. Krawiec ME, Westcott JY, Chu HW, Balzar S, Trudeau JB, Schwartz LB, Wenzel SE. Persistent wheezing in very young children is associated with lower respiratory inflammation. Am J Respir Crit Care Med 2001;163:1338-1343.

58. Arnoux B, Bousquet J, Rongier M, Scheinmann P, de Blic J. Increased bronchoalveolar lavage CD8 lymphocyte subset population in wheezy infants. Pediatr Allergy Immunol 2001;12:194-200.

59. Nagayama Y, Tsubaki T, Toba T, Nakayama S, Kiyofumi O. Analysis of sputum taken from wheezy and asthmatic infants and children, with special reference to respiratory infections. Pediatr Allergy Immunol 2001;12:318-326.

60. Chang AB, Cox NC, Faoagali J, Cleghorn GJ, Beem C, Ee LC, Withers GD, Patrick MK, Lewindon PJ. Cough and reflux esophagitis in children: their co-existence and airway cellularity. BMC Pediatr 2006;6:4.

61. Maclennan C, Hutchinson P, Holdsworth S, Bardin PG, Freezer NJ. Airway inflammation in asymptomatic children with episodic wheeze. Pediatr Pulmonol 2006;41:577-583.

62. Marchant JM, Masters IB, Taylor SM, Cox NC, Seymour GJ, Chang AB. Evaluation and outcome of young children with chronic cough. Chest 2006;129:1132-1141.

63. Donnelly D, Critchlow A, Everard ML. Outcomes in children treated for persistent bacterial bronchitis. Thorax 2007;62:80-84.

64. Byrnes C, Edwards E. Outcomes in children treated for persistent bacterial bronchitis. Thorax 2007;62:922-923, author reply 923.

65. Marchant JM, Gibson PG, Grissell TV, Timmins NL, Masters IB, Chang AB. Prospective assessment of protracted bacterial bronchitis: airway inflammation and innate immune activation. Pediatr Pulmonol 2008;43:1092-1099.

66. Khoshoo V, Edell D, Mohnot S, Haydel R Jr, Saturno E, Kobernick A Associated factors in children with chronic cough. Chest 2009;136: 811-815.

67. Rosen R, Johnston N, Hart K, Khatwa U, Katz E, Nurko S. Higher rate of bronchoalveolar lavage culture positivity in children with nonacid reflux and respiratory disorders. J Pediatr 2011;159:504-506.

68. Zgherea D, Pagala S, Mendiratta M, Marcus MG, Shelov SP Kazachkov M. Bronchoscopic findings in children with chronic wet cough. Pediatrics 2012;129:e364-e369.

69. Kompare M, Weinberger M. Protracted bacterial bronchitis in young children: association with airway malacia. J Pediatr 2012;160: 88-92.

70. Chang AB, Redding GJ, Everard ML. Chronic wet cough: protracted bronchitis, chronic suppurative lung disease and bronchiectasis. Pediatr Pulmonol 2008;43:519-531.

71. Marchant J, Masters IB, Champion A, Petsky H, Chang AB. Randomised controlled trial of amoxycillin clavulanate in children with chronic wet cough. Thorax 2012;67:689-693.

72. Gibson MK, Crofts TS, Dantas G. Antibiotics and the developing infant gut microbiota and resistome. Curr Opin Microbiol 2015;27: $51-56$.

73. Debley JS, Stamey DC, Cochrane ES, Gama KL, Redding GJ. Exhaled nitric oxide, lung function, and exacerbations in wheezy infants and toddlers. J Allergy Clin Immunol 2010;125:1228-1234.e13. 
74. Elliott M, Heltshe SL, Stamey DC, Cochrane ES, Redding GJ, Debley JS. Exhaled nitric oxide predicts persistence of wheezing, exacerbations, and decline in lung function in wheezy infants and toddlers. Clin Exp Allergy 2013;43:1351-1361.

75. Kurland G, Deterding RR, Hagood JS, Young LR, Brody AS, Castile RG, Dell S, Fan LL, Hamvas A, Hilman BC, et al.; American Thoracic Society Committee on Childhood Interstitial Lung Disease (chILD) and the chILD Research Network. An official American Thoracic Society clinical practice guideline: classification, evaluation, and management of childhood interstitial lung disease in infancy. Am J Respir Crit Care Med 2013;188:376-394.

76. Boyce JA, Assa'ad A, Burks AW, Jones SM, Sampson HA, Wood RA, Plaut M, Cooper SF, Fenton MJ, Arshad SH, et al. Guidelines for the diagnosis and management of food allergy in the United States: summary of the NIAID-sponsored expert panel report. Nutr Res 2011;31:61-75.

77. Miskelly FG, Burr ML, Vaughan-Williams E, Fehily AM, Butland BK, Merrett TG. Infant feeding and allergy. Arch Dis Child 1988;63: 388-393.

78. Chan YH, Shek LP, Aw M, Quak SH, Lee BW. Use of hypoallergenic formula in the prevention of atopic disease among Asian children. J Paediatr Child Health 2002;38:84-88.

79. Tromp II, Kiefte-de Jong JC, Lebon A, Renders CM, Jaddoe VW, Hofman A, de Jongste JC, Moll HA. The introduction of allergenic foods and the development of reported wheezing and eczema in childhood: the Generation R study. Arch Pediatr Adolesc Med 2011; 165:933-938.

80. Burr ML, Limb ES, Maguire MJ, Amarah L, Eldridge BA, Layzell JC, Merrett TG. Infant feeding, wheezing, and allergy: a prospective study. Arch Dis Child 1993;68:724-728.

81. James JM, Bernhisel-Broadbent J, Sampson HA. Respiratory reactions provoked by double-blind food challenges in children. Am J Respir Crit Care Med 1994;149:59-64.

82. Buts JP, Barudi C, Moulin D, Claus D, Cornu G, Otte JB. Prevalence and treatment of silent gastro-oesophageal reflux in children with recurrent respiratory disorders. Eur J Pediatr 1986;145:396-400.

83. Yüksel H, Yilmaz O, Kirmaz C, Aydoğdu S, Kasirga E. Frequency of gastroesophageal reflux disease in nonatopic children with asthmalike airway disease. Respir Med 2006;100:393-398.
84. Eid NS, Shepherd RW, Thomson MA. Persistent wheezing and gastroesophageal reflux in infants. Pediatr Pulmonol 1994;18:39-44.

85. Berquist WE, Rachelefsky GS, Kadden M, Siegel SC, Katz RM, Fonkalsrud EW, Ament ME. Gastroesophageal reflux-associated recurrent pneumonia and chronic asthma in children. Pediatrics 1981;68:29-35.

86. Ghezzi M, Silvestri M, Guida E, Pistorio A, Sacco O, Mattioli G, Jasonni V, Rossi GA. Acid and weakly acid gastroesophageal refluxes and type of respiratory symptoms in children. Respir Med 2011;105: 972-978.

87. Fohl AL, Regal RE. Proton pump inhibitor-associated pneumonia: not a breath of fresh air after all? World J Gastrointest Pharmacol Ther 2011;2:17-26.

88. Balson BM, Kravitz EK, McGeady SJ. Diagnosis and treatment of gastroesophageal reflux in children and adolescents with severe asthma. Ann Allergy Asthma Immunol 1998;81:159-164.

89. Arasu TS, Wyllie R, Fitzgerald JF, Franken EA, Siddiqui AR, Lehman GA, Eigen H, Grosfeld JL. Gastroesophageal reflux in infants and children comparative accuracy of diagnostic methods. J Pediatr 1980;96:798-803.

90. Patra S, Singh V, Chandra J, Kumar P, Tripathi M. Diagnostic modalities for gastro-esophageal reflux in infantile wheezers. $J$ Trop Pediatr 2011;57:99-103.

91. Karaman O, Uzuner N, Değirmenci B, Uğuz A, Durak H. Results of the gastroesophageal reflux assessment in wheezy children. Indian $J$ Pediatr 1999;66:351-355.

92. Thomas EJ, Kumar R, Dasan JB, Kabra SK, Bal CS, Menon S, Malhothra A. Gastroesophageal reflux in asthmatic children not responding to asthma medication: a scintigraphic study in 126 patients with correlation between scintigraphic and clinical findings of reflux. Clin Imaging 2003;27:333336.

93. Mercado-Deane MG, Burton EM, Harlow SA, Glover AS, Deane DA, Guill MF, Hudson V. Swallowing dysfunction in infants less than 1 year of age. Pediatr Radiol 2001;31 423-428.

94. Sheikh S, Allen E, Shell R, Hruschak J, Iram D, Castile R, McCoy K. Chronic aspiration without gastroesophageal reflux as a cause of chronic respiratory symptoms in neurologically normal infants. Chest 2001;120:1190-1195. 